\title{
Review
}

\section{In vitro fertilization in Japan - Early days of in vitro fertilization and embryo transfer and future prospects for assisted reproductive technology -}

\author{
By Masakuni SuZukI*1,†
}

(Communicated by Nobutaka HiRokAwA, M.J.A.)

\begin{abstract}
Assisted reproductive technology (ART) such as in vitro fertilization (IVF) and embryo transfer (ET) has been essential in the treatment of infertility. The world's first IVF-ET baby was born in 1978 based on the technique developed by Dr. Robert Edwards and Dr. Patrick Steptoe. ${ }^{1)}$ In Japan, the first IVF-ET birth was reported in 1983 by Prof. Masakuni Suzuki at Tohoku University School of Medicine. ${ }^{2), 3)}$

IVF-ET is a procedure used to achieve pregnancy that consists of extracting oocytes from an infertile woman, fertilizing them in vitro, and transferring fertilized eggs into the patient's uterine cavity (Fig. 1). Since the first report of successful IVF-ET, numerous techniques related to ART, such as cryopreservation of oocytes and embryos, gamete intrafallopian transfer (GIFT), and microinsemination, have been developed and refined (Table 1).

Herein we describe the history of basic research in IVF-ET that led to human applications, how the birth of the first IVF-ET baby was achieved in Japan, the current status of ART in Japan, issues related to ART, and future prospects for ART.
\end{abstract}

Keywords: IVF in Japan, first successful IVF in Japan, early days of IVF

I. In vitro fertilization (IVF) - from basic research to clinical application in humans

1. Basic research of IVF. During ovulation, secondary oocytes are released in a biologically stationary state during the metaphase of meiosis II. When a sperm fuses with an oocyte in this state, it is activated and meiosis resumes. The first half of fertilization, until a sperm fuses with an oocyte, is controlled by the dynamics of the sperm.

Mammalian sperm, unlike those of other vertebrates such as fish, completely lack the ability to fertilize when they leave the male's body. They acquire this ability while traveling through the female genital tract, such as in the uterus or fallopian tube. This phenomenon, called sperm capacitation, was discovered by an American researcher, M. C. Chang, in rabbits ${ }^{4}$ and by an Australian researcher, C. R. Austin, in rats, ${ }^{5)}$ both in 1951. In 1963, R.

\footnotetext{
*1 Emeritus Professor of Tohoku University, Miyagi, Japan. Correspondence should be addressed: M. Suzuki, Suzuki Memorial Hospital, 3-5-5 Satonomori, Iwanuma, Miyagi 989-2481, Japan (e-mail: masakuni@suzukihp.or.jp).
}

Yanagimachi and M. C. Chang ${ }^{6)}$ reported that capacitation can be induced in vitro under specific culture medium conditions. Their report triggered the advancement of both basic and applied research in IVF in various animals, including humans.

The acrosome reaction refers to morphological changes that occur in the sperm head when it fuses with the oocyte. Markedly increased sperm motility is called hyperactivation. Both phenomena are necessary for fertilization. J. C. Dan first described the acrosome reaction in sea urchin sperm in $1954,{ }^{7)}$ and hyperactivation was first reported in hamster sperm by $\mathrm{R}$. Yanagimachi in $1970 .^{8)}$

2. Efforts toward IVF in mammals. After the discovery of capacitation, in vitro induction of capacitation, and the elucidation of various phenomena in sperm during fertilization, many researchers began studying IVF in a large variety of mammals. These significant basic research contributions advanced the understanding of the mechanisms underlying fertilization and reproduction, which also advanced the fields of animal husbandry and breeding. 


\section{Day 1 of menstruation}

\section{A: Induction of ovulation}

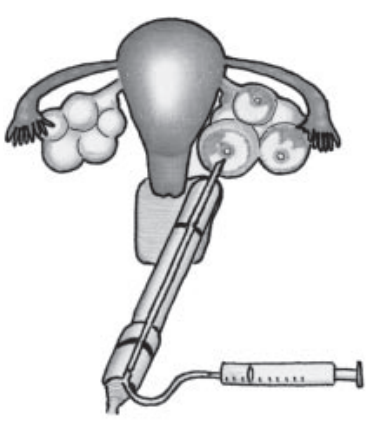

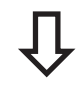

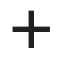

(1)measurement of follicle size

B: Testing (2)analyze of serum $\mathrm{E}_{2}$ (3)analyze of urinary LH

\section{G: Confirmation of fertilization}

(1 day after oocyte retrieval)

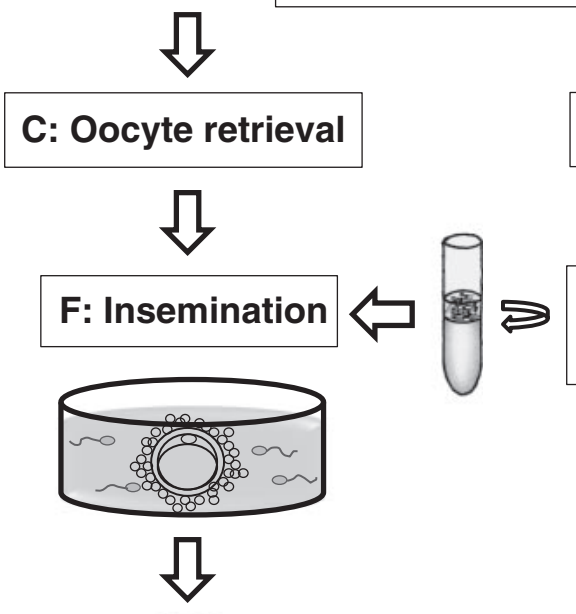

D: Semen collection

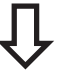

E: Sperm preparation (centrifuged at $400 \mathrm{~g}$ for $30 \mathrm{~min}$.)

\section{H: Embryo transfer}

( 3 or 5 days after oocyte retrieval)

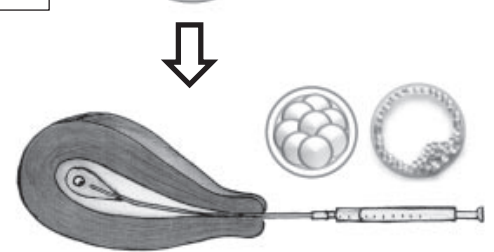

Fig. 1. In vitro fertilization and embryo transfer process. A: Induction of ovulation: After menstruation, ovulation is induced to produce multiple oocytes. B: Testing: 1. Follicular diameter is measured using ultrasound. 2. Blood estradiol $\left(\mathrm{E}_{2}\right)$ levels are measured. 3. Oocyte maturity is assessed with urinary Luteinizing Hormone (LH) measurements. C: Oocyte retrieval: Ultrasound-guided transvaginal follicle puncture is used to collect oocytes. D: Semen collection: Semen is collected from the husband. E: Sperm preparation: Semen is separated into multiple layers on a thickener effluent, and separated using a centrifuge. $(400 \times g, 30 \mathrm{~min})$. F: Insemination: The semen and oocytes are placed together in a dish with culture media. G: Confirmation of fertilization Fertilization is confirmed on the first day after oocyte retrieval. H: Embryo transfer: On the third or fifth day after oocyte retrieval, fertilized eggs are transferred to the uterus through a catheter.

Table 1. Timeline of reproductive technologies in Japan

\begin{tabular}{lll}
\hline 1983 & First baby conceived through in vitro fertilization was born & Tohoku University (Sendai, Miyagi Prefecture) \\
\hline 1985 & First baby born using gamete intrafallopian transfer & Koshigaya Municipal Hospital (Koshigaya, Saitama Prefecture) \\
\hline 1989 & First baby born from embryo cryopreservation and transfer & Tokyo Dental College Ichikawa General Hospital (Tokyo) \\
\hline 1992 & First baby born from microinsemination (zona opening method) & Suzuki Memorial Hospital (Iwanuma, Miyagi Prefecture) \\
\hline 1994 & $\begin{array}{l}\text { First baby born from microinsemination (intracytoplasmic } \\
\text { sperm injection) }\end{array}$ & $\begin{array}{l}\text { Fukushima Medical University (Fukushima, Fukushima } \\
\text { Prefecture) }\end{array}$ \\
\hline 2001 & $\begin{array}{l}\text { First baby born from in vitro fertilization after cryopreservation } \\
\text { of mature oocytes }\end{array}$ & Suzuki Memorial Hospital (Iwanuma, Miyagi Prefecture) \\
\hline
\end{tabular}


3. History of IVF-ET research in humans and its success. M. F. Menkin and J. Rock reported the first human IVF procedure using ejaculated sperm and follicles in 1944 and 1948. ${ }^{9)}$ Efforts toward human IVF-ET started in the 1960s following success in animal models. ${ }^{10), 11)}$ After overcoming the persistent obstacles of miscarriage and heterotopic pregnancy, Louise Brown was born in 1978 in the United Kingdom as the first IVF-ET baby. This was reported by P. C. Steptoe and R. G. Edwards, who performed IVF-ET on a 36-year-old woman with tubal infertility. ${ }^{1)}$

In Japan, researchers at Tohoku University, Toho University, and Kyoto University were pioneers in basic research on human IVF. A fundamental work on human IVF was first reported by Dr. Iritani in japan at the 24th Annual Meeting of the Japan Society of Fertility and Sterility in 1979. In the lecture, clear evidence of early events of IVF, female and male pronuclei and sperm midpiece were shown and considerable high fertility (19/48), 39.6\% was reported. ${ }^{12), 13)}$ The first successful case of human IVF-ET was reported by our group at Tohoku University in 1983. ${ }^{2), 3)}$ Following four successful cases of IVF-ET at Tohoku University, a collaborative group of physicians from Keio University and Tokyo Dental College succeeded in human IVF-ET, followed by another successful case at Tokushima University. A baby was born at each institution in March 1984.

4. Improved IVF-ET and new IVF-ET technology. In their initial successful IVF-ET procedure, P. C. Steptoe and R. G. Edwards collected oocytes during a natural ovulation period using a laparoscope. They inseminated the oocytes with washed sperm. After 72 hours, eight-cell stage embryos were transplanted into the uterine cavity. We basically followed the same procedure, except that clomiphene was used to stimulate the ovary in our case. In the United States, Jones et al. ${ }^{14)}$ used human menopausal gonadotropin to stimulate the ovary. Subsequently, combined use of human menopausal gonadotropin and a gonadotropin-releasing hormone $(\mathrm{GnRH})$ agonist $^{15)}$ was developed. Recently, GnRH antagonists $^{16)}$ have also been utilized, with better results in follicular maturation and the prevention of side effects including ovarian hyperstimulation syndrome.

During the early stages of clinical IVF, oocytes were collected by laparotomy. Subsequently, laparoscopic transabdominal-transvesicle follicle puncture guided by transabdominal ultrasound ${ }^{17)}$ was devel- oped. Later, laparoscopic transabdominal ultrasound-guided transvaginal follicle puncture ${ }^{18)}$ was utilized, followed by the development of transvaginal probes for ultrasonography. Eventually transvaginal ultrasound-guided transvaginal follicle puncture became available ${ }^{19)}$; this technique places less strain on patients and is now widely used.

Regarding cryopreservation of surplus embryos, a slow freezing technique using programmed freezers (computer-controlled freezers) was first used. This was replaced with vitrification, ${ }^{20)}$ which is much simpler and provides better post-thaw embryo survival rates. The dissemination of vitrification has allowed cryopreservation of oocytes and embryos at many institutions.

At first, embryos at the four to eight-cell stage were commonly transferred into the uterus. The development of new culture media and drastic improvements in culture technique have allowed embryos to grow into blastocysts in vitro. ${ }^{21)}$ Blastocyst transfer into the uterus has improved implantation rates; moreover, transplantation of a single blastocyst has improved the pregnancy rate to the point that it is equal to or better than that of traditional ET of multiple early embryos. This has significantly reduced the number of multiple pregnancies. ${ }^{22-24)}$ In addition, assisted hatching, which involves creating a defect in the zonapellucida of embryos cultured in vitro in order to improve implantation rates, has been developed. ${ }^{25)}$

In 1984, GIFT, in which fertilization and the growth of fertilized eggs are promoted in the patient's oviduct, was reported. ${ }^{26)}$ Several variations of GIFT, including zygote intrafallopian transfer, ${ }^{27)}$ pronuclear stage tubal transfer, ${ }^{28)}$ tubal embryo stage transfer, ${ }^{29)}$ were developed. However, the clinical use of GIFT and related techniques is becoming extremely rare due to drastic improvements in implantation rates associated with IVF-ET.

Since the number of sperm required for IVF is quite small (approximately 50,000), IVF-ET is also useful for treating male infertility. However, there are many conditions causing male infertility in which even 50,000 sperm cannot be obtained, or only low quality sperm are available despite sufficient numbers. IVF is ineffective in such cases. To overcome this difficulty in treating male infertility, a new ART technique, microinsemination, has been developed. Variations of microinsemination in clinical use include: zona pellucida drilling, ${ }^{30)}$ partial zona dissection, ${ }^{31)}$ and zona opening, ${ }^{32,33)}$ all of which promote the passage of sperm through the zona 
pellucida; and subzonal sperm insertion, ${ }^{34)}$ by which motile sperm are injected into the perivitelline space using a micropipette. Subsequently, intracytoplasmic sperm injection (ICSI), ${ }^{35)}$ in which a spermatozoon is directly injected into an oocyte, was attempted. ICSI was demonstrated to be much safer and more effective than other microinsemination techniques. Therefore, ICSI is now regarded as synonymous with microinsemination.

\section{History of IVF until the first birth of a baby via IVF in Japan}

1. Background on why IVF attracted so much attention.

1.1. Demographics of Japan. According to the Census Report in 1970 published by the Statistics Bureau in the Ministry of Internal Affairs and Communications of Japan, $10.9 \%$ of married women at that time did not have children. This number included married couples who were using birth control as well as those who lost babies due to miscarriage, premature birth, stillbirth, and postnatal death. However, it was believed that a large proportion of married couples without children were infertile.

Female fertility, the ability to become pregnant, is highest in the 20s and continues to be strong into the early 30s. However, in the late 30 s it suddenly becomes difficult to become pregnant. In the $40 \mathrm{~s}$ a decrease in fertility is evident. According to the demographics report (1980) on Japan, there were 13 million women under 40 years of age. Based on the fact that approximately $10 \%$ of married couples do not have children, there were approximately 1.3 million childless couples where the wife was of childbearing age.

1.2. Serious emotional distress in infertile couples. Since infertile couples appear normal, infertility was not considered a disease when medical knowledge was limited. However, with medical advances, it has been recognized that infertility is caused by various disorders.

In fact, the vast majority of infertile married couples suffer from psychological stress or emotional pain. As medical doctors, we have always felt that we have a duty to relieve such emotional pain in infertile couples whenever possible.

1.3. Survey on the concerns of infertile patients. ${ }^{36)}$ To learn about the emotional state of infertile women, we conducted a questionnaire survey of 300 patients with infertility seen at the Department of Gynecology and Obstetrics at Tohoku University
Hospital in March and April of 1983. This period includes March 14, 1983, when the first Japanese IVF pregnancy was reported.

The survey results are as follows: 1) $99.7 \%$ answered yes to "Have you heard of the term IVF?"; 2) $97 \%$ answered yes to "Do you know how IVF is performed and how IVF works?"; 3) "From which news source did you learn about IVF?" resulted in $72 \%$ for television, $64 \%$ for newspaper, and $10 \%$ for obstetrician/gynecologist; 4) $92 \%$ responded yes to "Do you accept IVF as infertility therapy?"; 5) 73\% answered yes and 3\% answered no to "Are you willing to undergo IVF if it were the only method for you to become pregnant?"; 6) $12 \%$ answered yes and $64 \%$ answered no to "Are you willing to undergo artificial insemination with donor sperm (AID) if it were the only method for you to become pregnant?"; 7) 4\% answered yes and $75 \%$ answered no to "Are you willing to use surrogacy if it were the only method for you to have a baby?"; 8) for "What do you think is good about IVF?" $67 \%$ responded with "We can have children with the same genetic material" and $59 \%$ responded "A woman can become pregnant even if the spouse has oligozoospermia"; 9) for "What do you think is bad or concerning about IVF?" $68 \%$ responded with "There is a possible risk of having a baby with a chromosomal abnormality or birth defects", $44 \%$ responded with "Only a limited number of institutions offer IVF", and $29 \%$ responded with "Our case may be reported in the newspaper or on television"; and 10) for "What do you expect from IVF?" $83 \%$ responded with "A higher success rate".

\section{Road to the formulation of the IVF-ET}

\section{Charter.}

2.1. Incorporating advanced knowledge about IVFET from abroad and the debate on ethical issues regarding IVF-ET. In October 1979, the Ninth World Congress of Gynecology and Obstetrics was held in Tokyo. Two notable physicians who visited Sendai while attending the congress were Dr. Patrick Steptoe from the United Kingdom, who was actively working on IVF, and Dr. Vandeville from the United States, who was opposed to IVF on ethical grounds.

Dr. Steptoe stated his strong belief that patients with infertility also have the right to make a family and IVF-ET is the only method for women with tubal infertility who cannot become pregnant through any other methods to have an opportunity at pregnancy. In response, Dr. Vandeville expressed the dissenting view that research on other methods for treating such patients should be pursued. In addition, Dr. 
Vandeville noted that excessively difficult tests beyond the scope of average physicians are often required in therapy for infertility, and further research may therefore be necessary to develop new tests that can be more easily performed.

Around that time, many Japanese physicians were in favor of putting a decision regarding IVFET on hold. In this context, two world-renowned physicians, one who supported and the other who opposed IVF-ET, attended the congress. We Japanese physicians at the congress carefully reviewed these two physicians' arguments as well as differences in religion, ethics, and the social context across nations, and ultimately decided on the direction in which we should proceed. The general consensus policy was that we should perform IVF-ET in clinical practice only to help patients with untreatable tubal infertility.

2.2. Initiating acquisition of medical skills and discussion of ethical issues related to IVF-ET. In 1981, three of us from Tohoku University School of Medicine visited Monash University in Australia to discuss ethical issues and obtain knowledge related to IVF-ET. In those days, ethical issues related to IVFET were almost resolved in Australia. The information from Monash University was so well organized that it was instrumental in helping us formulate the Tohoku University Charter on IVF-ET.

In parallel to the formulation of ethical guidelines on IVF-ET, we were working hard toward clinical application of IVF-ET. In February 1982, in order to learn oocyte retrieval methods using laparoscopic surgery and culture techniques for oocytes and embryos, several staff physicians at Tohoku University School of Medicine visited overseas institutions practicing cutting-edge IVF-ET techniques. In addition to acquiring those skills, they obtained technical documents on IVF-ET, as well as various resources on ethical, legal, religious, and social issues related to IVF-ET.

At that time in Japan, preparations were underway for the inauguration of the Japan Society of Fertilization and Implantation. A seminar on IVF-ET was held in October 1982. Legal scholars, sociologists, and pathologists gather to actively exchange opinions on medical ethics and ethical issues related to IVF-ET based on their respective perspectives.

2.3. Codification of the Tohoku University Charter on IVF-ET. Five years prior to the first clinical use of IVF-ET, we at the Department of Gynecology and Obstetrics of Tohoku University had already begun discussing the international situation and ethical issues related to IVF-ET. With the information on IVF-ET that we had collected over a long period of time, we consulted with notable experts and researchers in countries with advanced IVF-ET technologies and referred to the guidelines for IVF therapy established by the Japan Society of Obstetrics and Gynecology (JSOG) in 1982 and the issues related to IVF-ET that were discussed by the Japan Society of Fertilization and Implantation. Eventually, the Tohoku University Charter on IVF-ET (Table 2) was codified on January 1, 1983 at Tohoku University. Prior to this Charter, there had been no ethical guidelines for regulating new medical practices such as IVF-ET in Japan. This Charter has since become the basis for many ethical guidelines on IVFET adopted in Japan.

This Charter was published in March 1983, at the same time as the announcement of the first successful IVF-ET pregnancy in Japan. Some claimed that we should have published the Charter much earlier; however, we had decided to publish it concurrently with the first successful IVF-ET pregnancy because the establishment of ethical guidelines alone would not benefit the public before IVF-ET can be shown to lead to a successful pregnancy.

3. Formulation of IVF-ET treatment guidelines at Tohoku University. In the Department of Gynecology and Obstetrics at Tohoku University, we had thoroughly reviewed the basic IVF-ET research that we had conducted over the several years prior, as well as numerous academic papers published in countries with advanced IVF-ET research. Consequently, since the mid 1980s we were confident that patients with untreatable tubal infertility due to bilateral tubal obstruction could become pregnant through IVF-ET. In those days, however, a majority of Japanese physicians were against the clinical use of IVF-ET. Thus, we had to proceed with caution because the time for clinical IVF-ET therapy was not ripe yet. This opposition began to wane near the end of 1982, just after the inauguration of the Japan Society of Fertilization and Implantation.

Triggered by the news of the first successful IVFET procedure in Japan at Tohoku University, which was announced throughout Japan on March 14, 1983, many patients from all over Japan with intractable infertility sought treatment at Tohoku University Hospital. However, since there was limited capacity at Tohoku University Hospital, we codified the Guidelines for IVF-ET Treatment (Table 3) on June 1, 1983, as an interim solution. 
Table 2. Charter on in vitro fertilization and embryo transfer (IVF-ET)

I Basic philosophy of IVF-ET

1. IVF-ET is performed as a medical therapy.

2. IVF-ET is performed for the purpose of contributing to the happiness of infertile patients.

3. IVF-ET is performed in compliance with the standards promulgated by the Japan Society of Obstetrics and Gynecology.

Appendix 1. Standards promulgated by the Japan Society of Obstetrics and Gynecology

1. Prior to clinical practice, quality control for IVF-ET shall be carried out using animal models.

2. IVF-ET shall be performed in conditions where a physician is responsible for all manipulations and processing.

3. Patient consent shall be obtained after a full explanation of the methods and expected results.

4. Handle cases of discontinuation during the in vitro fertilization phase with due care.

5. The women should be legally married couples. Procedures should not be performed outside of marriage.

6. If there are any questions, consult with this Society.

Fully confirm the safety of equipment, manipulations, and culture techniques using animal models, e.g., mice.

4. Manipulations that may affect genes should not be performed during IVF-ET.

II Guidance on the implementation of IVF-ET

1. The physician engaging in IVF-ET shall endeavor to gain a high level of knowledge and technical proficiency in reproductive medicine.

2. When performing IVF-ET, the physician in charge of each program shall carry out their responsibilities in the spirit of cooperation and betterment of medicine.

3. In order to prevent arm to patients undergoing IVF-ET, operations shall be performed by a specifically certified physician.

4. An accurate and thorough clinical evaluation shall be performed prior to IVF-ET in order to formulate the optimal treatment strategy.

5. IVF-ET is appropriate for the treatment of infertility due to fallopian tube dysfunction considered to be intractable even with salpingoplasty.

6. IVF-ET shall only be performed when the following conditions are met:

a. The couple is legally married, and both spouses wish to raise the child.

b. The patient is healthy enough for pregnancy, and can deliver and raise a child, both mentally and physically.

c. The patient's uterus is suitable for implantation and maintaining a pregnancy.

d. The patient has ovaries from which mature oocytes can be collected.

e. Usable sperm can be obtained from the patient's spouse.

III Patient management in IVF-ET

1. IVF-ET should be fully explained to the patient and her spouse so that they can gain a thorough understanding.

2. The intentions of the patient and her spouse shall be respected when deciding whether to perform IVF-ET and the operative method.

3. A consent form with the approval of the patient and her spouse for IVF-ET shall be prepared.

4. IVF-ET may require many continuous cycles over a long period of time in order to result in a pregnancy. Seek to provide as much assistance as possible to the patient and her spouse in order to overcome any mental strain during this period.

5. Provide counselors who are knowledgeable in IVF-ET to handle various mental, physical, and social problems related to IVF-ET.

The counselor shall provide assistance according to the patient's request.

6. The medical staff involved in IVF-ET shall not disclose any confidential patient information, as regulated by law.

7. When a patient becomes pregnant via IVF-ET, long-term health management to prevent problems during the course of the pregnancy, delivery, and development of the child shall be provided.

Note: This charter shall become effective as of January 1, 1983.

Department of Gynecology and Obstetrics, Tohoku University School of Medicine

(Head professor, Masakuni Suzuki)

\section{Hardships encountered by staff members who worked on IVF-ET.}

4.1. Irregular work. Most medical services are usually conducted during the daytime, except for emergency medical care. When we started IVFET treatments, however, our IVF-ET techniques, including control of ovulation, were immature; therefore, some procedures such as oocyte retrieval, 
Table 3. Guidelines for in vitro fertilization and embryo transfer (IVF-ET) treatment

1. IVF-ET shall also be performed in the following cases:

a. When accurate and sufficient clinical testing has been performed on both the husband and wife, and diagnosis of infertility that cannot be treated using any method other than IVF-ET is made.

Note: Clinical evaluation is to include diagnostic laparoscopy.

1) In cases of tubal infertility where pregnancy via salpingoplasty is deemed not possible.

2) In cases of infertility due to oligozoospermia where pregnancy by sperm-sorting and concentration methods and artificial insemination by the husband is deemed not possible.

3) In cases of infertility where the cause cannot be determined from the results of a full clinical evaluation, and pregnancy has not

been achieved even after all other treatments have been attempted over a long period of time.

b. In cases where both husband and wife want a child.

c. In cases where the wife is in healthy enough for pregnancy, and can deliver and raise a child, both mentally and physically.

d. In cases where sufficient explanation regarding IVF-ET methods and the expected probability of pregnancy has been provided to the couple, and consent has been obtained.

2. IVF-ET is not to be performed in the following cases:

a. Condition of the wife

1) 35 years of age or older when applying for treatment

2) Severe periovular adhesions or ovulation disorder where oocyte retrieval is not possible.

3) Abnormality of the uterus where implantation is not possible and it is impossible to maintain a pregnancy.

b. Condition of the husband

Severe abnormality of sperm or seminal fluid where fertilization is not possible.

c. Other: cases where pregnancy via IVF-ET is virtually impossible.

3. For couples who wish to undergo IVF-ET and meet the conditions above, the following procedures shall be performed:

a. Initiation of treatment shall be determined in the order of applications received.

b. In principle, treatment shall be performed in three cycles (over a total of three months).

c. When a patient does not become pregnant after three months of treatment, a waiting period of 3-12 months shall be used to allow for recovery of bodily strength.

Note: This guideline on treatment has been in effect since June 1, 1983. A partial revision was made on August 1, 1983.

Department of Gynecology and Obstetrics, Tohoku University School of Medicine

confirmation of fertilization, medium exchange, and embryo transfer were often carried out late at night.

4.2. Difficulties in medium preparation. It is important that the culture media for oocytes and embryos does not contain substances unnecessary for their growth. In the 1980s, before culture media were commercially available, we formulated media inhouse using various available agents. However, no agents specifically intended for media were available, so we used agents with the highest purity available.

In addition, it was difficult to obtain highly purified water that is key to medium formulation. There were no satisfactory sources of water in Japan. Fortunately, we had a chance to obtain water used at a whisky distillery in Scotland, which allowed us to formulate the media necessary for achieving a certain level of results.

\section{The first successful IVF-ET pregnancy in} Japan.

5.1. Background on the first patient who became pregnant via IVF-ET. In October 1982, a woman who was childless for eight years of marriage visited the Department of Gynecology and Obstetrics at Tohoku University Hospital. Three years after marriage, she underwent salpingoplasty at another institution, and subsequently received treatment for infertility at yet another institution without becoming pregnant. She was diagnosed with tubal infertility based on laparoscopic findings. She was counseled by an attending physician that pregnancy was extremely unlikely with another salpingoplasty, but was offered IVF-ET as a new treatment option, albeit with not very high pregnancy rates. After discussion with her husband, she decided to receive IVF-ET treatment. 
5.2. IVF-ET treatment course. In January 1983 the patient received the first course of IVF-ET treatment but it was unsuccessful. She wished to try another course of IVF-ET. Her menses began on January 22. We administered $100 \mathrm{mg}$ of clomiphene for five days starting on the fifth day of the menstrual cycle and measured follicular diameter using ultrasonography. Starting at 06:00 on the 13th day of the menstrual cycle, we measured urinary luteinizing hormone (LH) levels every four hours using a semiquantitative method. The initiation of the LH surge was confirmed at 21:00 on the 14th day. At 00:30 on the 16th day, we retrieved one oocyte from the patient using laparoscopy. We then obtained one fertilized egg after insemination, and transplanted the four-cell stage embryo into the uterine cavity at $12: 45$ on the 18th day. The urinary gonadotropin (hCG) level was $80 \mathrm{IU} / \mathrm{L}$ on the 31st day, confirming pregnancy. Subsequently, hCG values increased smoothly to $640 \mathrm{IU} / \mathrm{L}$ on the 34 th day and 1000 $\mathrm{IU} / \mathrm{L}$ on the 38 th day. During the sixth week of pregnancy, we observed a gestational sac, thus clinically confirming her pregnancy. Fetal heart movement was detected in the seventh week. ${ }^{2)}$

5.3. Announcement of the first IVF-ET pregnancy in Japan. One day after we confirmed fetal heart movement, we announced to the media that a woman who was unable to get pregnant with existing treatment methods became pregnant through IVFET at Tohoku University Hospital. This was the first successful IVF-ET pregnancy in Japan.

6. Social confusion caused by the announcement of the first successful IVF-ET pregnancy. The announcement of the first successful human pregnancy via IVF-ET in Japan garnered significant public attention. One possible reason was that some had fabricated medically impossible stories from the news of the pregnancy, which was reported as the insemination of a human oocyte in vitro and the transplantation of the fertilized egg into the uterine cavity. This resulted in increased public concerns about IVF-ET.

At the same time, women with intractable tubal infertility and men with oligozoospermia who gave up hope of childbearing through conventional treatment methods developed great expectations that IVF-ET treatment would allow them or their spouses to become pregnant.

\section{Training of ART medical staff}

In the $1980 \mathrm{~s}$, there were many academic societies and study groups on reproductive endocrinology, reproductive physiology, and infertility science. However, since there were continuous arguments for and against the clinical use of IVF-ET in Japan, hands-on training sessions for IVF-ET were rarely provided. In those days, only a limited number of medical institutions in Japan performed ART, although an increasing number of institutions were starting to incorporate ART into their medical practices. ART treatment outcomes were institution-dependent. ART was premature in general. Thus, physicians in Japan needed to improve the level of infertility treatment by improving their clinical skills, providing treatment at a larger number of institutions, innovating new treatment methods, and conducing further qualitative and quantitative research on ART.

In those days, many Japanese medical researchers and clinicians went abroad to learn theories, techniques, and ethical considerations of ART. This required significant time and expense, and it was still challenging to obtain good results despite the overseas training. To resolve these issues, many concerned stakeholders asked us to hold workshops on ART in Japan that are comparable to those offered in several foreign countries.

In consideration of the status of infertility treatment in Japan at that time and the dissemination of ART in the future, we organized a series of workshops focused on hands-on clinical training, which was called "Workshop for New Reproductive Technologies in Sendai". They have been held seven times since 1989. Unlike other academic conferences, this workshop was organized to educate and train medical staff in advanced treatment techniques and skills as well as to develop more effective treatment methods in order to improve a clinic's pregnancy rate using ART (Table 4). During the workshops, we employed simultaneous interpreters to help attendees better understand presentations by foreign lecturers.

\section{Current status of reproductive medicine in $\operatorname{Japan}^{24), 37)-59)}$}

1. ART Registry System established by JSOG. Currently, ART is an indispensable treatment for infertility. Many ART treatment techniques have been developed and refined since it was introduced in Japan in 1983.

In October 1983, JSOG announced its official position on IVF-ET and published "Remarks on IVFET". In March 1988, JSOG published a notification entitled "ART Registry System for Clinical IVF-ET Practice" as it introduced the ART Registry System. 
Table 4. Workshop for New Reproductive Technologies in Sendai, 1989-2001

\begin{tabular}{|c|c|c|c|}
\hline Year & Titles & Presenters & Country \\
\hline 1989 & Clinical Techniques of IVF, GIFT, PROST \& TEST & $\begin{array}{l}\text { John L. Yovich, MBBS, M.D, } \\
\text { FRCOG, FRACOG, MAIBiol }\end{array}$ & Australia \\
\hline 1989 & Laboratory Techniques of IVF, GIFT, PROST \& TEST & Jeanne M. Yovich, BSc & Australia \\
\hline 1989 & In Vitro Fertilization Past and Recent Development & Hung-Ching Liu, Ph.D. & U.S.A. \\
\hline 1989 & Human In Vitro Fertilization and Embryo Transfer & Mina Alikani, M. Sc. & U.S.A. \\
\hline 1990 & $\begin{array}{l}\text { Pelviscopy-Operative Guidelines for "Minimally Invasive Surgery" } \\
\text { following an Organ-oriented Classification }\end{array}$ & $\begin{array}{l}\text { o. Prof.Dr.med.Dr.med.vet.h.c. } \\
\text { Kurt Semm }\end{array}$ & West Germany \\
\hline 1990 & $\begin{array}{l}\text { Medico surgical Treatment of Genital Endometriosis Focusing Gestagens } \\
\text { and Anti-Gestagens Together with Surgical Pelviscopy }\end{array}$ & Prof. Dr. Liselotte Mettler & West Germany \\
\hline 1990 & 1. Clinical Practices in IVF and ET 2. Specific Areas of IVF Techniques & Prof. Dr. John Leeton & Australia \\
\hline 1990 & Micro-Insemination in In Vitro Fertilization & S. C. $\mathrm{Ng}$ & Singapore \\
\hline 1991 & $\begin{array}{l}\text { Laboratory Aspects of Human In Vitro Fertilization: Perspective } \\
\text { of a Gamete Biologist }\end{array}$ & $\begin{array}{l}\text { Thomas Huang Jr., Associate } \\
\text { Professor }\end{array}$ & U.S.A. \\
\hline 1991 & $\begin{array}{l}\text { The Diagnosis and Treatment of Male Infertility Utilizing Assisted } \\
\text { Reproductive Techniques }\end{array}$ & $\begin{array}{l}\text { Richard A. Bronson, M.D., } \\
\text { Associate Professor }\end{array}$ & U.S.A. \\
\hline 1991 & Endocrinology of IVF & David Healy, Ph.D. & Australia \\
\hline 1992 & The Current State of The Art in Sterility in Taiwan & Jau-Nan Lee, M.D., Professor & Taiwan \\
\hline 1992 & $\begin{array}{l}\text { Information on Diagnosis and Treatment of Infertility Including IVF } \\
\text { Program in Korea }\end{array}$ & Yoon Seok Chang, M.D., Professor & Korea \\
\hline 1992 & Practicalities of IVF & $\begin{array}{l}\text { Yvonne du Plessis, Laboratory } \\
\text { Manager }\end{array}$ & Australia \\
\hline 1992 & Surrogate Parenting: A Legal Approach to Resolving Infertility & Noel P. Keane, Executive Director & U.S.A. \\
\hline 1992 & $\begin{array}{l}\text { 1. Donor egg: a solution for premature ovarian failure patients. } \\
\text { 2. Strategies for improving implantation in IVF. }\end{array}$ & $\begin{array}{l}\text { Hung-Ching Liu, Ph.D., Director, } \\
\text { Professor }\end{array}$ & U.S.A. \\
\hline 1999 & Problems of gamete competence for fertilization: diagnosis and treatment & Jan Tesarik, M.D., Ph.D. & Spain \\
\hline 1999 & Optimizing the endometrial environment for embryo transfer & Christos Coutfaris, M.D., Ph.D. & U.S.A. \\
\hline 1999 & Azoospermia: current aspects and prospects & Herman Tournaye, M.D., Ph.D. & Belgium \\
\hline 1999 & Human blastocyst development In vitro without co-culture & Barry Behr, Ph.D., HCLD. & U.S.A. \\
\hline 1999 & Intracytoplasmic sperm injection (ICSI): where are the limits? & Herman Tournaye, M.D., Ph.D. & Belgium \\
\hline 1999 & $\begin{array}{l}\text { Molecular mechanisms of human trophoblast adhesion and migration } \\
\text { during implantation of the human embryo }\end{array}$ & Christos Coutfaris, M.D., Ph.D. & U.S.A. \\
\hline 1999 & $\begin{array}{l}\text { Problems of early embryo growth and implantation potential and their } \\
\text { possible solutions: embryo selection versus embryo rescue strategies }\end{array}$ & Jan Tesarik, M.D., Ph.D. & Spain \\
\hline
\end{tabular}

In 1989, the Committee on the Registration of Reproductive Medicine, which was supervised by the JSOG Board, analyzed registry reports on ART in Japan. In April 1990, the committee compiled and published the first report on the results of clinical implementation of ART treatment in Japan up to 1988. The committee continued to compile and publish reports until 1992. Since 1993, the Ethics Committee on ART Practice and Research took over responsibility for conducting comprehensive surveillance on ART through collecting registry data and ART results from all registered institutions. Detailed surveys on ART treatment were conducted at institutions selected by the Committee on Reproductive and Endocrine Medicine and institution-level results were published the JSOG's journal. In 1999, the Registration and Survey Subcommittee was formed after the reorganization of the Ethics Committee. 
Continued.

\begin{tabular}{llll}
\hline Year & \multicolumn{1}{c}{ Titles } & \multicolumn{1}{c}{ Presenters } & \multicolumn{1}{c}{ Country } \\
\hline 2000 & Transvaginal 3-D imaging in the evaluation and treatment of infertility & Wilfried Feichtinger, M.D. & Austria \\
\hline 2000 & Strategies to optimize outcome in IVF & $\begin{array}{l}\text { Salim Daya, MB ChB, MSc, } \\
\text { FRCSC, Professor }\end{array}$ & Canada \\
\hline 2000 & $\begin{array}{l}\text { Recent progress on medical drugs (particularly for recombinant FSH } \\
\text { "Gonal-F }{ }^{\circledR} \text { ") in the area of infertility and sterility }\end{array}$ & $\begin{array}{l}\text { Louis st. L.O'Dea, MB, BCh, } \\
\text { BAO.FRCP(C) }\end{array}$ & U.S.A. \\
\hline 2000 & Assisted Reproduction in Australia & Deborah Sherrin, Ms. & Australia \\
\hline 2000 & Recognition of embryos with implantation potential & Deborah Sherrin, Ms. & Australia \\
\hline 2000 & $\begin{array}{l}\text { Review of the theatment of anovulation using recombinant FSH with } \\
\text { and without GnRH analogues }\end{array}$ & $\begin{array}{l}\text { Louis st. L.O'Dea, MB, BCh, } \\
\text { BAO.FRCP(C) }\end{array}$ & U.S.A. \\
\hline 2000 & Treatment methods of assisted reproduction & Wilfried Feichtinger, M.D. & Austria \\
\hline 2000 & Hydrosalpinges and fertility potential & $\begin{array}{l}\text { Salim Daya, MB ChB, MSc, } \\
\text { FRCSC, Professor }\end{array}$ & Canada \\
\hline 2001 & ICSI: 3000 babies of follow up in Germany & Prof. Dr. med. K. Diedrich & Germany \\
\hline 2001 & IVF Failure With Good Quality Embryos: "Unexplained Or Undiagnosed" & Geoffrey Sher, M.D. & U.S.A. \\
\hline 2001 & GnRH-antagonists in IVF & Prof. Dr. med. K. Diedrich & Germany \\
\hline 2001 & $\begin{array}{l}\text { The present state of ART in Korea including surrogate mother and egg } \\
\text { donation }\end{array}$ & Shin Yong Moon, M.D., Ph.D. & Korea \\
\hline 2001 & Ovum Donation in the United States: Practical Considerations & Geoffrey Sher, M.D. & U.S.A. \\
\hline
\end{tabular}

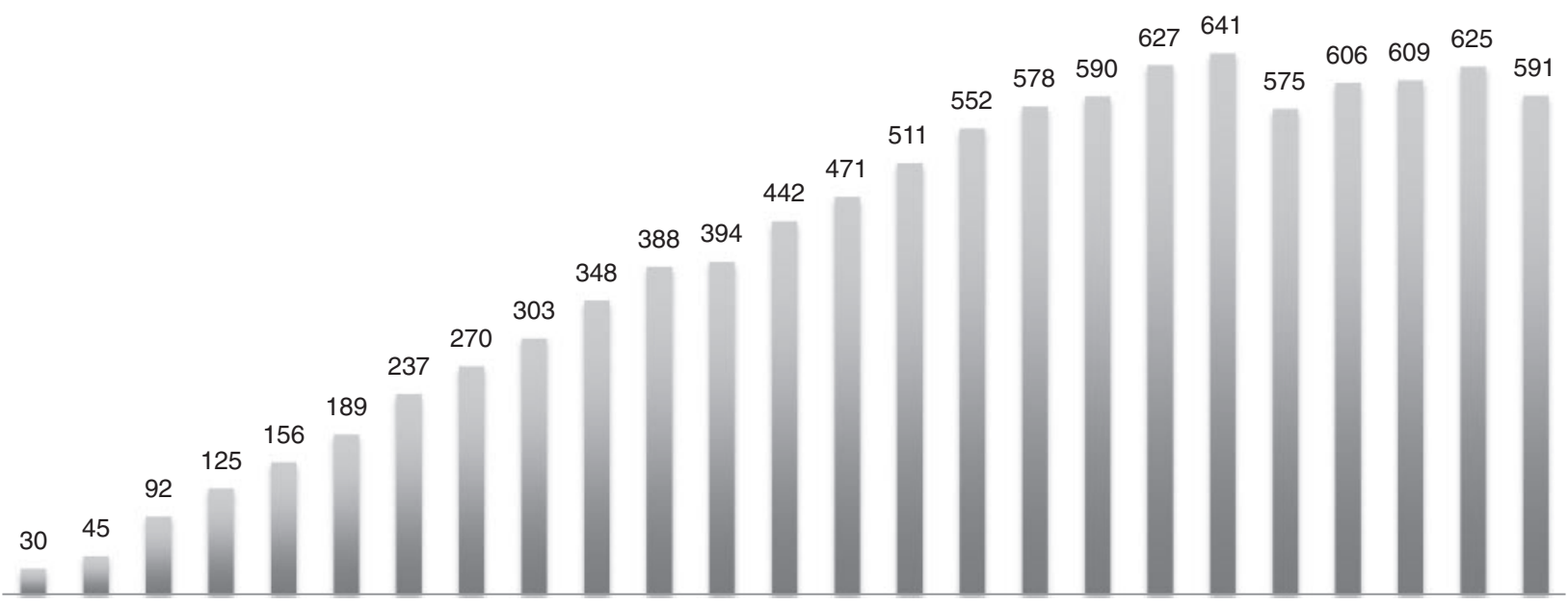

1986198719881989199019911992199319941995199619971998199920002001200220032004200520062007200820092010

Fig. 2. Number of registered ART institutions.

Since then, this subcommittee has been conducting comprehensive surveys on the clinical use of ART.

JSOG has been devoted to collecting and publishing as much information as possible regarding the state of ART in Japan in order to enhance awareness and understanding of ART in JSOG members and the public alike. In addition, in order to comprehend the current status of and safety evaluations regarding ART, and to formulate future treatment strategies involving ART, JSOG started a new registry in January 1, 2007 in which each patient's data is individually recorded.

2. Statistics on various ART treatment options.

2.1. Number of registered institutes (Fig. 2). As of the end of 1985, 30 institutions were registered in the ART Registry System. An increasing number of institutions have registered since then; 303 institutes 

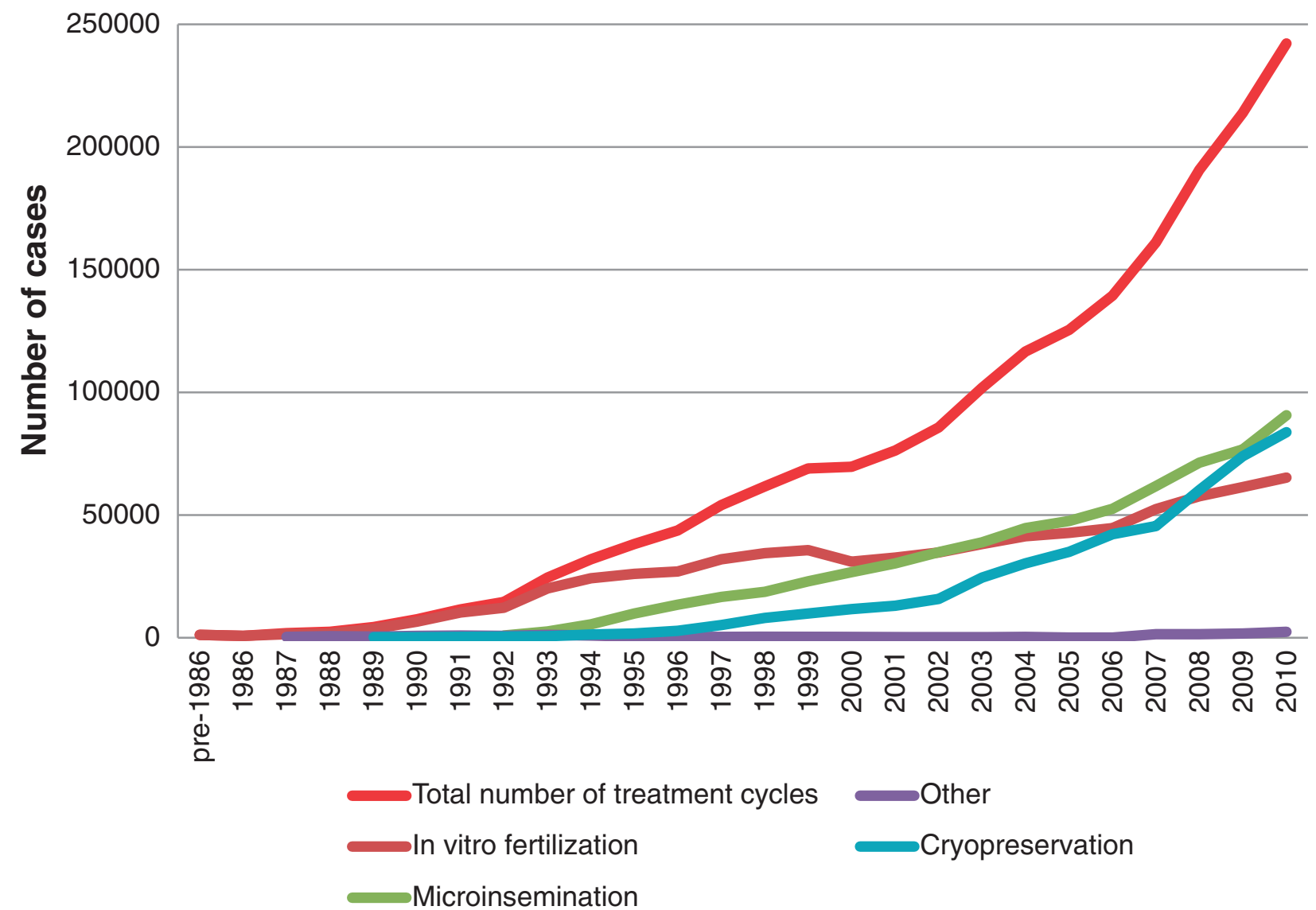

Fig. 3. Number of couples treated by ART methods annually.

(an approximately 10-fold increase) were registered by the 10th year of the registry in 1996, and 591 (an approximately 20-fold increase) were registered by the 25th year in 2010.

2.2. Number of IVF-ET patients (Fig. 3). When the ART Registry System was introduced in 1986, 752 patients had received IVF-ET treatment. The number of patients undergoing IVF-ET treatment drastically increased as the number of institutions offering the treatment increased. In 1991, approximately 10,000 patients had been treated, and in 2011 this number increased to 269,654 . Japan performs the most IVF-ET treatments in the world.

Detailed surveillance on infertility treatment using frozen embryos began in 1989. In that year, embryos were cryopreserved from 184 cycles and 92 ETs were performed, which resulted in three births. Until the early 2000s, the number of programmed freezers, which limited the dissemination of IVF-ET therapy and thus the number of cases, increased only at a slow pace. This situation was changed when vitrification, a new cryopreservation technique that did not require programmed freezers, became widely available for preserving oocytes and embryos in the early 2000s. This has allowed many institutions to offer cryopreservation. Consequently, the number of patients undergoing cryopreserved-thawed human embryo transfer (CR-ET) drastically increased. In 2008, the number of CR-ET treatments surpassed that of IVF-ET treatments. In 2011, the number of CR-ET treatments reached 95,764, which is the second most popular to microinsemination.

Since 1992, infertility treatment involving microinsemination has been surveyed. In 1992, there were a total of 963 treatment cycles involving microinsemination, which resulted in 35 confirmed births. Subsequently, this technique has been improved. In particular, ICSI, which is currently the mainstream of treatment, has become available as a microscopic technology. The main indication for ICSI is male infertility. The number of microinsemination treatments surpassed the number of IVF cycles in 2002. In 2011, microinsemination was used in 102,473 cases, dominating ART therapy. 


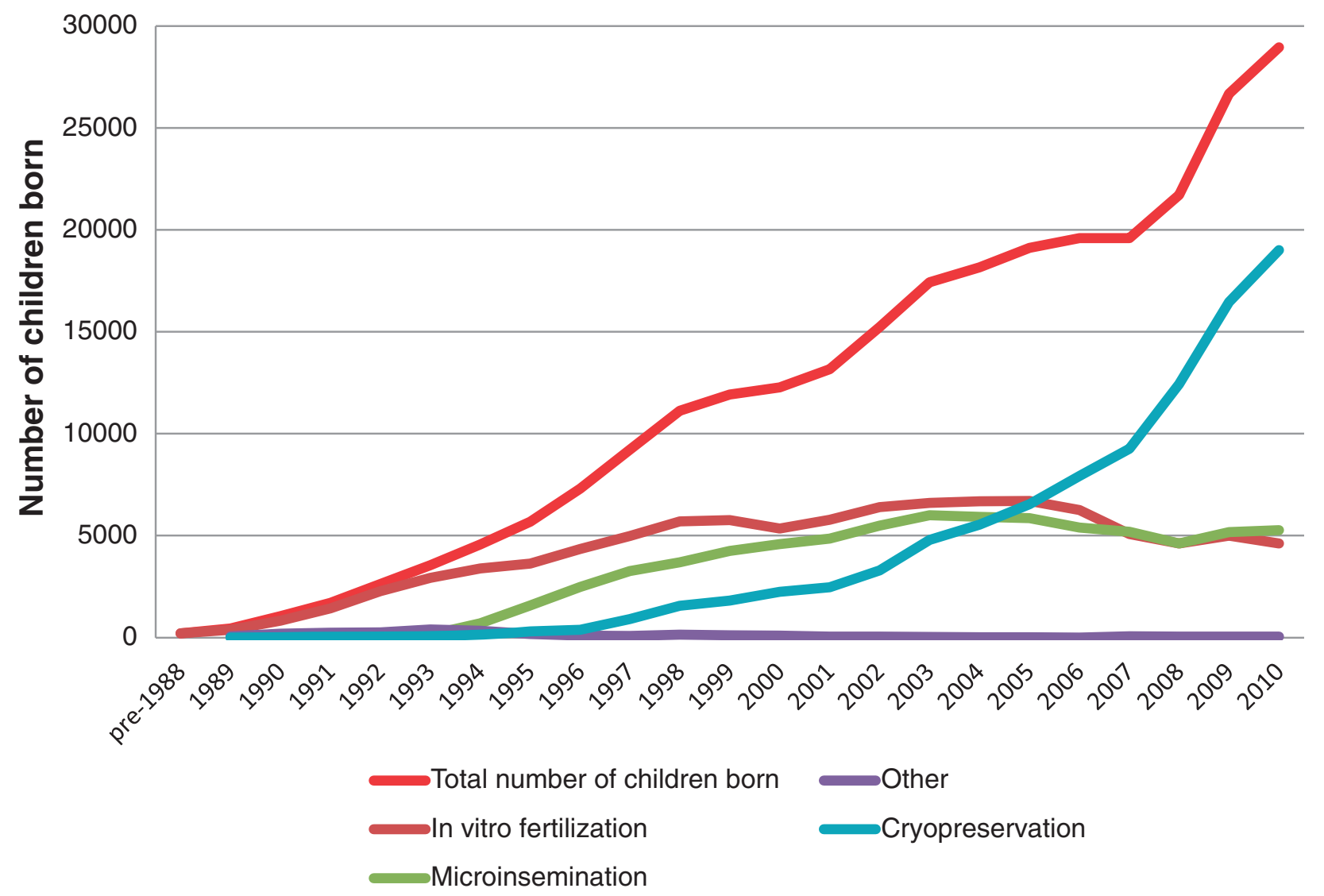

Fig. 4. Number of children born via each ART method annually.

2.3. Number of ART births (Fig. 4). In 1986, 16 babies were born via IVF-ET in Japan. In that year, the total number of births was 1,382,946, indicating that 1 in 86,434 births involved ART. Increases in the number of institutions offering ART and of patients undergoing treatment have both contributed to this rapid increase. In 2011, the number of births via ART was 32,426 , which corresponds to 1 in 32.6 total births (the total number of births was 1,050,806). In other words, 1 child in each classroom was born via ART. Through the end of 2011, a total of 303,806 babies have been born via ART. Thus, ART has helped ameliorate the low birth rate problem, a serious social issue that Japan is currently facing.

\section{Issues surrounding ART $\mathbf{A}^{60)-84)}$}

As previously mentioned, 1 in 32.6 babies were born via ART in Japan in 2011. It is fair to say that ART has become a routine practice for treating infertility; however, several issues still remain. I will divide the issues into three categories: (1) side effects of infertility treatment, (2) potential negative im- pacts on the next and subsequent generations, and (3) social and ethical issues.

Possible side effects may include multiple pregnancy, spontaneous abortion, preterm delivery, heterotopic pregnancy, and ovarian hyperstimulation syndrome. Multiple pregnancy was once a serious issue, but the incidence has drastically decreased since 2008, when JSOG announced at a conference that only one embryo at a time should be transplanted.

Table 5 summarizes the results of studies conducted by various groups evaluating potential negative impacts of ART on the next and subsequent generations. Many researchers have found a higher spontaneous abortion rate with ART, leading to a concern over a possible increase in the rate of chromosomal abnormalities.

In Japan, ART is not legally controlled by legislation. Rather, it is self-regulated through various guidelines on reproductive medicine formulated and issued by JSOG. Recently, social and ethical issues related to ART in which the uterus or gametes from a surrogate are utilized have gained 
Table 5. Safety of in vitro fertilization and embryo transfer

\begin{tabular}{|c|c|c|}
\hline & In vitro fertilization & Microinsemination \\
\hline \multirow[t]{2}{*}{ Chromosomal abnormalities } & No change & Increased (Approximately 3-fold) \\
\hline & & Increased when testicular spermatozoa are used \\
\hline \multirow[t]{5}{*}{ Congenital abnormalities } & No change & No change \\
\hline & & Higher in male offspring \\
\hline & & Musculoskeletal, cardiovascular, and genitourinary system \\
\hline & & abnormalities are common \\
\hline & & Common when immature testicular spermatozoa are used \\
\hline Spontaneous abortion & Increased (1.5-fold) & Increased $(1.5$-fold $)$ \\
\hline \multirow[t]{2}{*}{ Long-term prognosis of the child } & No change & No change \\
\hline & & $\begin{array}{l}\text { Cognitive ability, social and emotional growth, athletic ability, } \\
\text { and physiological, neurological, and psychomotor evaluations } \\
\text { are normal }\end{array}$ \\
\hline Fertility of the child & Unknown & Unknown \\
\hline
\end{tabular}

Note 1: The rate of multiple births is significantly higher in children who are conceived through in vitro fertilization and microinsemination ( $20 \%$ vs. $2.0 \%$ in controls). Consequently, the incidence of preterm birth increases in children who are conceived through in vitro fertilization and microinsemination ( $29.3 \%$ with in vitro fertilization, $31.8 \%$ with microinsemination). As a result, perinatal abnormalities such as very low birth weight have increased.

Note 2: It is unclear whether the fusion of two embryos (biovular monochorionic twins [chimera]) is the cause.

Note 3: Imprinting abnormality. Beckwith-Wiedemann syndrome, Angelman syndrome.

Note 4: Propagation of infertility. Male infertility caused by Y chromosome microdeletions, Klinefelter syndrome.

(Hoshi K. 2011 ${ }^{82)}$ )

prominent attention. In October 1998, the Special Committee for Medically Assisted Reproduction was established by the Health Sciences Council for Evaluating Advanced Medical Techniques to address issues related to ART from the perspective of experts on reproductive medicine. In April 2003, the committee released many announcements related to ART in which surrogates are involved. They stated that (1) the use of sperm, oocytes, or embryos obtained from surrogates is allowed, (2) the use of technologies related to cytoplasmic transfer and cell nuclear replacement are prohibited until further notice, (3) surrogate conception is prohibited, (4) compensation for providing sperm, oocytes, or embryos is prohibited, (5) the anonymity of gamete donors should be protected, (6) the use of sperm or oocytes from siblings is prohibited until further notice, and (7) a person born via ART has a right to request disclosure of information on gamete donors. However, these guidelines are not legally enforceable because they are not legislated, and a private association organized by institutions that conduct ART has different opinions. Many challenges with ART involving surrogates have been reported. There remains a potential for unpredictable complicated issues, such as risks related to pregnancy and delivery and complex family-related issues.

\section{Future directions in reproductive medicine}

Currently, it is not possible for married couples that lack a uterus or gametes to have their own children without the assistance of a third person. However, researchers are investigating methods of producing germ cells from somatic cells by applying regenerative medicine techniques in patients who do not have gametes.

\section{Conclusions}

It has been 35 years since the first IVF baby in the world was born in the United Kingdom and 30 years since the first IVF baby was delivered in Japan at the Department of Gynecology and Obstetrics at Tohoku University School of Medicine. Since then, over four million babies have been born around the world using ART. IVF babies were once called "test tube babies" and regarded as special, but now there is one in each classroom. IVF-ET to treat infertility has gained wide societal acceptance.

In a report published on February 21, 2011, the Ministry of Land, Infrastructure, Transport and Tourism of Japan suggested the possibility that the Japanese population, which peaked in 2004, will continue to decrease in the next 100 years to the same level as 100 years ago (during the latter half of the 
Meiji Period). This degree of population change, even over millennia, is extremely drastic. The Japanese population will decrease by approximately 33 million ( $25.5 \%$ decrease) to 95.2 million in $2050 .{ }^{85)}$ In other words, Japan will experience an unprecedented drastic population decrease. Given such predictions, I believe that ART such as IVF-ET is not only related to concerns of individual families but also an invaluable technology that can help bring about future generations who will forge the future of Japan.

I wonder what ART and children born via ART will be like 30 years from now. Will pre-implantation genetic diagnosis be performed before ET in all patients? Will the production of gametes from somatic cells be a common practice? Ultimately, reproductive medicine will certainly significantly assist married couples who suffer from refractory infertility; however, at the same time, some are concerned about the possibility that it may encourage mechanistic reproduction without accompanying sexual love between men and women. As a matter of fact, many children born via ART today will reach marriageable age and then middle age. In Japan, only two cases have been reported, both at our institution, in which children who were born via IVF-ET had children through natural conception. ${ }^{86)}$ Therefore, we cannot claim that the role of IVF-ET is assured. Life produced via ART will be passed to subsequent generations. Therefore, it is important for us to continue to watch how children born via ART develop.

\section{Acknowledgements}

I would like to express my sincere thanks to the late Dr. Gregory Pincus of the Worcester Foundation for Experimental Biology, who taught me the physiology of germ cells essential for IVF; the late Dr. Patrick Steptoe and the late Dr. Robert Edwards of the Bourn Hall Clinic, who instructed me in the clinical medicine of IVF; and Dr. Ryuzo Yanagimachi at Hawaii University, who advised me on the clinical use of IVF. My special thanks are also extended to the staff members of the Department of Gynecology and Obstetrics and the Department of Anesthesiology at Tohoku University School of Medicine who dedicated themselves to IVF research and clinical application day and night in order to achieve the first successful IVF birth in Japan.

\section{References}

1) Steptoe, P.C. and Edwards, R.G. (1978) Birth after the reimplantation of a human embryo. Lancet $\mathbf{2}$, 366 .
2) Suzuki, M., Hoshi, K., Hoshiai, H., Saito, A., Momono, K., Mori, R., Kyono, K., Tsuiki, A., Imaizumi, H., Nagaike, H., Uehara, S., Naganuma, T. and Hirose, Y. (1983) Pregnancy achieved through in vitro fertilization and embryo transfer. Jpn. J. Fert. Steril. 28, 439-443.

3) Suzuki, M., Hoshiai, H., Hoshi, K., Saito, A., Uehara, S. and Tsuiki, A. (1984) In vitro fertilization and Embryo Transfer at Tohoku University, Sendai, Japan. J. In vitro Fert. Embryo Transf. 1, 82.

4) Chang, M.C. (1951) Fertilizing capacity of spermatozoa deposited into the fallopian tubes. Nature 168, 697-698.

5) Austin, C.R. (1951) Observations on the penetration of the sperm in the mammalian egg. Aust. J. Sci. Res. B 4, 581-596.

6) Yanagimachi, R. and Chang, M.C. (1963) Fertilization of hamster eggs in vitro. Nature 200, 281282.

7) Dan, J.C. (1952) Studies on the acrosome. I. Reaction to egg water and other stimuli. Biol. Bull. 103, 54-66.

8) Yanagimachi, R. (1970) The movement of golden hamster spermatozoa before and after capacitation. J. Reprod. Fertil. 23, 193-196.

9) Menkin, M.F., Rock, J. (1948) In vitro fertilization and cleavage of human ovarian eggs. Am. J. Obstet. Gynecol. 55, 440-452.

10) Edwards, R.G., Donahue, R.P., Baramki, T.A. and Jones, H.W. Jr. (1966) Preliminary attempts to fertilize human oocyte matured in vitro. Am. J. Obstet. Gynecol. 96, 192-200.

11) Edwards, R.G., Bavister, B.D. and Steptoe, P.C. (1969) Early stages of fertilization in vitro of human oocytes matured in vitro. Nature 221, $632-635$.

12) Iritani, A. (1979) Present condition of in vitro fertilization. 24th Annual Meeting of Japan Soc. Fert. Steril.

13) Nishimoto, T., Yamada, I., Niwa, K., Mori, T., Nishimura, T. and Iritani, A. (1982) Sperm penetration in vitro of human oocytes matured in a chemically defined medium. J. Reprod. Fertil. 64, 115-119.

14) Jones, H.W. Jr., Jones, G.S., Andrews, M.C., Acosta, A., Bundren, C., Garcia, J., Sandow, B., Veeck, L., Wilkes, C., Witmyer, J., Wortham, J.E. and Wright, G. (1982) The program for in vitro fertilization at Norfolk. Fertil. Steril. 38, 14-21.

15) Porter, R.N., Smith, W., Craft, I.L., Abdulwahid, N.A. and Jacobs, H.S. (1984) Induction of ovulation for in-vitro fertilization using buserelin and gonadotropins. Lancet 2, 1284-1285.

16) Itskovitz-Eldor, J., Kol, S., Mannaerts, B. and Coelingh Bennink, H. (1982) First established pregnancy after controlled ovarian hyperstimulation with recombinant follicle stimulating hormone and the gonadotropin-releasing hormone antagonist ganirelix (Org 37462). Hum. Reprod. 13, 294295.

17) Lenz, S. and Lauritsen, J.G. (1982) Ultrasonically guided percutaneous aspiration of human follicles 
under local anesthesia: a new method of collecting oocytes for in vitro fertilization. Fertil. Steril. 38, 673-677.

18) Gleicher, N., Friberg, J., Fullan, N., Giglia, R.V., Mayden, K., Kesky, T. and Siegel, I. (1983) EGG retrieval for in vitro fertilization by sonographically controlled vaginal culdocentesis. Lancet $\mathbf{2}$, 508-509.

19) Wikland, M., Enk, L. and Hamberger, L. (1985) Transvesical and transvaginal approaches for the aspiration of follicles by use of ultrasound. Ann. N. Y. Acad. Sci. 442, 182-194.

20) Gordts, S., Roziers, P., Campo, R. and Noto, V. (1990) Survival and pregnancy outcome after ultra rapid freezing of human embryos. Fertil. Steril. 53, 469-472.

21) Gardner, D.K., Schoolcraft, W.B., Wagley, L., Schlenker, T., Stevens, J. and Hesla, J. (1998) A prospective randomized trial of blastocyst culture and transfer in in-vitro fertilization. Hum. Reprod. 13, 3434-3440.

22) Shulman, A., Ben-Nun, I., Ghetler, Y., Kaneti, H., Shilion, M. and Beyth, Y. (1993) Relationship between embryo morphology and implantation rate after in vitro fertilization treatment in conception cycles. Fertil. Steril. 60, 123-126.

23) Gardner, D.K., Vella, P., Lane, M., Wagley, L., Schlenker, T. and Schoolcraft, W.B. (1998) Culture and transfer of human blastocysts increases implantation rate and reduces the need for multiple embryo transfers. Fertil. Steril. 69, 84-88.

24) Saito, H. (2010) Status of ART based on data from the ART Registry System. Acta Obstet. Gynaecol. Jpn. 62, 739-745.

25) Cohen, J., Eisner, C., Kort, H., Malter, H., Massey, J., Mayer, M.P. and Wiemer, K. (1990) Impairment of the hatching process following IVF in the human and improvement of implantation by assisting hatching using micromanipulation. Hum. Reprod. 5, 7-13.

26) Asch, R.H., Ellsworth, L.R., Balmaceda, J.P. and Wong, P.C. (1984) Pregnancy after trans laparoscopic gamete intrafallopian transfer. Lancet 2, $1034-1035$.

27) Devroey, P., Brackmans, P., Smith, J., Van Waesberghe, L., Wisanto, A., Van Steirteghem, A., Heytens, L. and Camu, F. (1986) Pregnancy after trans laparoscopic zygote intrafallopian transfer in a patient with sperm antibodies. Lancet I, 1929

28) Yovich, J.L., Blackledge, D.G., Richardson, P.A., Matson, P.L., Turner, S.R. and Draper, R. (1987) Pregnancies following pronuclear stage tubal transfer. Fertil. Steril. 48, 851-857.

29) Balmaceda, J.P., Gastaldi, C., Remohi, J., Borrero, C., Ord, T. and Asch, R.H. (1988) Tubal embryo transfer as a treatment for infertility due to male factor. Fertil. Steril. 50, 476-479.

30) Cohen, J., Alikani, M., Trowbridge, J. and Rosenwaks, Z. (1992) Implantation enhancement by selective assisted hatching using zona drilling of human embryos with poor prognosis. Hum.
Reprod. 7, 685-691.

31) Cohen, J., Malter, H., Fehilly, C., Wright, G., Elsner, C., Kort, H. and Massey, J. (1988) Implantation of embryos after partial opening of oocyte zonapellucida to facilitate sperm penetration. Lancet $2,162$.

32) Odawara, Y. and Lopata, A. (1989) A zona opening procedure for improving in vitro fertilization at low sperm concentrations: A mouse model. Fertil. Steril. 51, 699-704.

33) Odawara, Y., Tachibana, I., Suzuki, M., Chida, S., Hiruta, M., Iida, S., Watanabe, Y., Mori, S. and Suzuki, M. (1993) Improving fertilization rate in vitro of severe male factor patients by zona opening methods. J. Fertil. Implantation 10, 279281.

34) Ng, S.C., Bongso, A. and Ratnum, S.S. (1988) Pregnancy after transfer of sperm under zona pellucida. Lancet ii, 790 .

35) Palermo, G., Joris, H., Devroey, P. and Van Steirteghem, A.C. (1992) Pregnancies after intracytoplasmic injection of single spermatozoon into an oocyte. Lancet 340, 17-18.

36) Yokaichiya, T., Kyono, K., Momono, K., Hoshi, K. and Suzuki, M. (1983) Survey on the attitudes of infertile women regarding in vitro fertilization and embryo transfer. Jpn. J. Fertil. Steril. 28, 571.

37) Japan Society of Obstetrics and Gynecology (1990) Committee report on the reproductive medicine registry. Acta Obstet. Gynaecol. Jpn. 42, 393-397.

38) Japan Society of Obstetrics and Gynecology (1991) Committee report (1990) on the reproductive medicine registry (Results on clinical practice in 1989 and survey results on children born via infertility treatment as of the end of 1988). Acta Obstet. Gynaecol. Jpn. 43, 470-476.

39) Japan Society of Obstetrics and Gynecology (1992) Committee report (1991) on the reproductive medicine registry (3rd ed.) (Results on clinical practice in 1990 and survey results on children born via infertility treatment in 1989). Acta Obstet. Gynaecol. Jpn. 44, 499-511.

40) Japan Society of Obstetrics and Gynecology (1993) Committee report (1992) on the reproductive medicine registry (4th ed.) (Results on clinical practice in 1991, survey results on children born via infertility treatment in 1990, and results from comprehensive analysis of survey data on all children born via infertility treatment to date). Acta Obstet. Gynaecol. Jpn. 45, 397-410.

41) Japan Society of Obstetrics and Gynecology (1994) Ethics Committee report on medical care and research in 1993 (Results on clinical application of in vitro fertilization and embryo transfer in 1992). Acta Obstet. Gynaecol. Jpn. 46, 929-933.

42) Japan Society of Obstetrics and Gynecology (1995) Ethics Committee report on medical care and research in 1994 (Results on clinical application of in vitro fertilization and embryo transfer in 1993). Acta Obstet. Gynaecol. Jpn. 47, 444-448.

43) Japan Society of Obstetrics and Gynecology (1996) Ethics Committee report on medical care and research in 1995 (Results on clinical application of 
in vitro fertilization and embryo transfer in 1994). Acta Obstet. Gynaecol. Jpn. 48, 365-371.

44) Japan Society of Obstetrics and Gynecology (1997) Ethics Committee report on medical care and research in 1996 (Results on clinical application of in vitro fertilization and embryo transfer in 1995). Acta Obstet. Gynaecol. Jpn. 49, 697-702.

45) Japan Society of Obstetrics and Gynecology (1998) Ethics Committee report on medical care and research in 1997 (Results on clinical application of in vitro fertilization and embryo transfer in 1996 and a list of registered institutions as of March 1998). Acta Obstet. Gynaecol. Jpn. 50, 267-277.

46) Japan Society of Obstetrics and Gynecology (1999) Ethics Committee report on medical care and research in 1998 (Results on clinical application of in vitro fertilization and embryo transfer in 1997 and a list of registered institutions as of March 1999). Acta Obstet. Gynaecol. Jpn. 51, 361-394.

47) Ethics Committee of the Japan Society of Obstetrics and Gynecology (2000) Subcommittee report on registration and survey of ART in 1999 (Results on clinical application of in vitro fertilization and embryo transfer in 1998 and a list of registered institutions as of March 2000). Acta Obstet. Gynaecol. Jpn. 52, 962-987.

48) Ethics Committee of the Japan Society of Obstetrics and Gynecology (2001) Subcommittee report on registration and survey of ART in 2000 (Results on clinical application of in vitro fertilization and embryo transfer in 1999 and a list of registered institutions as of March 2001). Acta Obstet. Gynaecol. Jpn. 53, 1462-1493.

49) Ethics Committee of the Japan Society of Obstetrics and Gynecology (2003) Subcommittee report on registration and survey of ART in 2001-2002 (Results on clinical application of in vitro fertilization and embryo transfer in 2000-2001 and a list of registered institutions as of March 2003). Acta Obstet. Gynaecol. Jpn. 55, 1272-1287.

50) Ethics Committee of the Japan Society of Obstetrics and Gynecology (2005) Subcommittee report on registration and survey of ART in 2003 (Results on clinical application of in vitro fertilization and embryo transfer in 2002 and a list of registered institutions as of October 2004). Acta Obstet. Gynaecol. Jpn. 57, 118-146.

51) Ethics Committee of the Japan Society of Obstetrics and Gynecology (2005) Subcommittee report on registration and survey of ART in 2004 (Results on clinical application of in vitro fertilization and embryo transfer in 2003 and a list of registered institutions as of June 2005). Acta Obstet. Gynaecol. Jpn. 57, 1601-1629.

52) Ethics Committee of the Japan Society of Obstetrics and Gynecology (2006) Subcommittee report on registration and survey of ART in 2005 (Results on clinical application of in vitro fertilization and embryo transfer in 2004 and a list of registered institutions as of June 2006). Acta Obstet. Gynaecol. Jpn. 58, 1554-1579.

53) Ethics Committee of the Japan Society of Obstetrics and Gynecology (2007) Subcommittee report on registration and survey of ART in 2006 (Results on clinical application of in vitro fertilization and embryo transfer in 2005 and a list of registered institutions as of July 2007). Acta Obstet. Gynaecol. Jpn. 59, 1717-1739.

54) Ethics Committee of the Japan Society of Obstetrics and Gynecology (2008) Subcommittee report on registration and survey of ART in 2007 (Results on clinical application of in vitro fertilization and embryo transfer in 2006 and a list of registered institutions as of March 2008). Acta Obstet. Gynaecol. Jpn. 60, 1230-1253.

55) Ethics Committee of the Japan Society of Obstetrics and Gynecology (2009) Subcommittee report on registration and survey of ART in 2008 (Results on clinical application of in vitro fertilization and embryo transfer in 2007 and a list of registered institutions as of July 2009). Acta Obstet. Gynaecol. Jpn. 61, 1853-1880.

56) Ethics Committee of the Japan Society of Obstetrics and Gynecology (2010) Subcommittee report on registration and survey of ART in 2009 (Results on clinical application of in vitro fertilization and embryo transfer in 2008 and a list of registered institutions as of July 2010). Acta Obstet. Gynaecol. Jpn. 62, 1821-1848.

57) Ethics Committee of the Japan Society of Obstetrics and Gynecology (2011) Subcommittee report on registration and survey of ART in 2010 (Results on clinical application of in vitro fertilization and embryo transfer in 2009 and a list of registered institutions as of July 2011). Acta Obstet. Gynaecol. Jpn. 63, 1881-1911.

58) Ethics Committee of the Japan Society of Obstetrics and Gynecology (2012) Subcommittee report on registration and survey of ART in 2011 (Results on clinical application of in vitro fertilization and embryo transfer in 2010 and a list of registered institutions as of July 2012). Acta Obstet. Gynaecol. Jpn. 64, 2110-2140.

59) Ethics Committee of the Japan Society of Obstetrics and Gynecology (2013) Subcommittee report on registration and survey of ART in 2012 (Results on clinical application of in vitro fertilization and embryo transfer in 2011 and a list of registered institutions as of July 2013). Acta Obstet. Gynaecol. Jpn. 65, 2083-2115.

60) Liebaers, I. (1993) VIIIth World Congress on In Vitro Fertilization and Alternate Assisted Reproduction. Oral Communications Kyoto.

61) Bonduelle, M., Legein, J., Buysse, A., Van Assche, E., Wisanto, A., Devroey, P., Van Steirteghem, A.C. and Liebaers, L. (1996) Prospective follow-up study of 423 children born after intracytoplasmic sperm injection. Hum. Reprod. 11, 1558-1564.

62) Palermo, G.D., Colombero, L.T., Schattman, G.L., Davis, O.K. and Rosenwaks, Z. (1996) Evolution of pregnancies and initial follow-up of newborns delivered after intracytoplasmic sperm injection. JAMA 276, 1893-1897.

63) Kurinczuk, J.J. and Bower, C. (1997) Birth defects in 
infants conceived by intracytoplasmic sperm injection: an alternative interpretation. BMJ 315, 1260-1265; Bonduelle, M., Devroey, P., Liebaers, I. and Van Steirteghem, A. (1997) Commentary: major defects are overestimated. BMJ 315, 12651266.

64) Coulam, C.B., Opsahl, M.S., Sherins, R.J., Thorsell, L.P., Dorfmann, A., Krysa, L., Fugger, E. and Schulman, J.D. (1996) Comparisons of pregnancy loss patterns after intracytoplasmic sperm injection and other assisted reproductive technologies. Fertil. Steril. 65, 1157-1162.

65) Bernardini, L., Martini, E., Geraedts, J.P., Hopman, A.H., Lanteri, S., Conte, N. and Capitanio, G.L. (1997) Comparison of gonosomal aneuploidy in spermatozoa of normal fertile men and those with severe male factor detected by in-situ hybridization. Mol. Hum. Reprod. 3, 431-438.

66) Storeng, R.T., Plachot, M., Theophile, D. Mandelbaum, J., Belaisch-Allart, J. and Vekemans, M. (1998) Incidence of sex chromosome abnormalities in spermatozoa from patients entering an IVF or ICSI protocol. Acta Obstet. Gynecol. Scand. 77, 191-197.

67) Colombero, L.T., Hariprashad, J.J., Tsai, M.C., Rosenwaks, Z. and Palermo, G.D. (1999) Incidence of sperm aneuploidy in relation to semen characteristics and assisted reproductive outcome. Fertil. Steril. 72, 90-96.

68) Persson, J.W., Peters, G.B. and Saunders, D.M. (1996) Is ICSI associated with risks of genetic disease? Implications for counselling, practice and research. Hum. Reprod. 11, 921-924.

69) Testart, J., Gautier, E., Brami, C., Rolet, F., Sedbon, E. and Thebault, A. (1996) Intracytoplasmic sperm injection in infertile patients with structural chromosome abnormalities. Hum. Reprod. 11, 2609-2612.

70) Mau, U.A., Backert, I.T., Kaiser, P. and Kiesel, L. (1997) Chromosomal findings in 150 couples referred for genetic counselling prior to intracytoplasmic sperm injection. Hum. Reprod. 12, 930-937.

71) Van der Ven, K., Montag, M., Peschka, B., Leygraaf, J., Schwanitz, G., Haidl, G., Krebs, D. and van der Ven, H. (1997) Combined cytogenetic and Y chromosome microdeletion screening in males undergoing intracytoplasmic sperm injection. Mol. Hum. Reprod. 3, 699-704.

72) Pauer, H.U., Hinney, B., Michelmann, H.W., Krasemann, E.W., Zoll, B. and Engel, W. (1997) Relevance of genetic counselling in couples prior to intracytoplasmic sperm injection. Hum. Reprod. 12, 1909-1912.

73) Van der Ven, K., Peschka, B., Montag, M., Lange, R., Schwanitz, G. and van der Ven, H.H. (1998) Increased frequency of congenital chromosomal aberrations in female partners of couples undergoing intracytoplasmic sperm injection. Hum. Reprod. 13, 48-54.

74) Meschede, D., Lemcke, B., Exeler, J.R., De Geyter, C., Behre, H.M., Nieschlag, E. and Horst, J. (1998)
Chromosome abnormalities in 447 couples undergoing intracytoplasmic sperm injection-prevalence, types, sex distribution and reproductive relevance. Hum. Reprod. 13, 576-582.

75) Tuerlings, J.H., de France, H.F., Hamers, A., Hordijk, R., Van Hemel, J.O., Hansson, K., Hoovers, J.M., Madan, K., Van der BlijPhilipsen, M., Gerssen-Schoorl, K.B., Kremer, J.A. and Smeets, D.F. (1998) Chromosome studies in 1792 males prior to intracytoplasmic sperm injection: the Dutch experience. Eur. J. Hum. Genet. 6, 194-200.

76) Scholtes, M.C., Behrend, C., Dietzel-Dahmen, J., van Hoogstraten, D.G., Marx, K., Wohlers, S., Verhoeven, H. and Zeilmaker, G.H. (1998) Chromosomal aberrations in couples undergoing intracytoplasmic sperm injection: influence on implantation and ongoing pregnancy rates. Fertil. Steril. 70, 933-937.

77) In't Veld, P.A., van Opstal, D., Van den Berg, C., Van Ooijen, M., Brandenburg, H., Papers, L., Jahoda, M.G., Stijnen, T.H. and Los, F.J. (1995) Increased incidence of cytogenetic abnormalities in chorionic villus samples from pregnancies established by in vitro fertilization and embryo transfer (TVF-ET). Prenat. Diagn. 15, 975-980.

78) Van Opstal, D., Los, F.J., Ramlakhan, S., Van Hemel, J.O., Van Den Ouweland, A.M., Brandenburg, H., Pieters, M.H., Verhoeff, A., Vermeer, M.C., Dhont, M. and In't Veld, P.A. (1997) Determination of the parent of origin in nine cases of prenatally detected chromosome aberrations found after intracytoplasmic sperm injection. Hum. Reprod. 12, 682-686.

79) Nagafuchi, S., Namiki, M., Nakahori, Y., Kondoh, N., Okuyama, A. and Nakagome, Y. (1993) A minute deletion of the $\mathrm{Y}$ chromosome in men with azoospermia. J. Urol. 150, 1155-1157.

80) Vogt, P.H., Edelmann, A., Kirsch, S., Henegariu, O., Hirschmann, P., Kiesewetter, F., Köhn, F.M., Schill, W.B., Farah, S., Ramos, C., Hartmann, M., Hartschuh, W., Meschede, D., Behre, H.M., Castel, A., Nieschlag, E., Weidner, W., Gröne, H.J., Jung, A., Engel, W. and Haidl, G. (1996) Human Y chromosome azoospermia factors (AZF) mapped to different subregions in Yq11. Hum. Mol. Genet. 5, 933-943.

81) Sutcliffe, A.G. and Ludwig, M. (2007) Outcome of assisted reproduction. Lancet 370, 351-359.

82) Hoshi, K. and Kubo, H. (2000) The Effect of the Pregnancy after Intracytoplasmic Sperm Infection on the Next Generation. Acta Obstet. Gynaecol. Jpn. 52, 183.

83) Ichikawa, T., Utsunomiya, T., Odawara, Y., Saito, H., Nakamura, Y. and Mori, T. (2005) Japan Society of Fertilization and Implantation Survey Committee Report on the postnatal development of children born via assisted reproduction technologies performed in 1997. October 8.

84) Hoshi, K. (2011) Reproductive Medicine: Past, present, and future. Acta Obstet. Gynaecol. Jpn. 63, 1936-1955. 
85) Ministry of Land, Infrastructure, Transport and Tourism of Japan, National Land Development Council Policy Unit, Long-term Outlook Committee. (2010) Interim report on the long-term outlook of Japan.

86) Suzuki, M., Tachibana, I., Noda, T. and Imaizumi, H. (2009) Spontaneous pregnancy and delivery by a mother who was born via in vitro fertilization/ embryo transfer (IVF). Tohoku J. Exp. Med. 218, 81.

(Received Jan. 10, 2014; accepted Feb. 12, 2014)

\section{Profile}

Masakuni Suzuki was born in Sendai, Miyagi Prefecture, Japan on May 21, 1921. In 1946 he graduated from the University of Tokyo School of Medicine. In the same year he joined the Departments of Electrophysiology and Gynecology and Obstetrics at Tohoku University as a staff physician. He received a Ph.D. in Medicine from the University of Tohoku in 1955 and held a one-year postdoctoral position at the Worcester Reproductive Endocrinology Center (Director, Dr. G. Pincus) in the United States starting in 1961. After returning to Japan, he became a professor in the Department of Obstetrics and Gynecology, Niigata University School of Medicine, in 1963. In 1970 he moved to the Department of Gynecology and Obstetrics at the Tohoku University School of Medicine. After obtaining tenure, he traveled extensively to attend various international

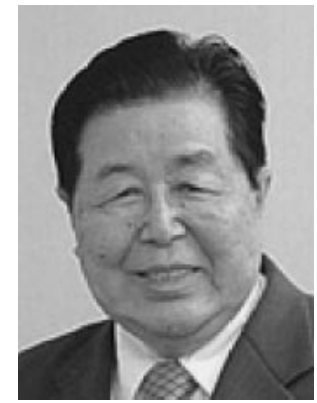
conferences concerning research in human reproductive medicine in approximately 50 countries. During that period, he improved techniques for clinical IVF-ET. As a professor, he has mentored many medical researchers. In 1962, he won a gold medal as part of the Tohoku University School of Medicine Scholarship for his basic research on sex hormone therapy. Between 1961 and 1970, he had received a grant each year from the Population Council (New York) for his research on ovulation and central nervous system function. In 1983, his pioneering work on IVF-ET led to the successful pregnancy and delivery of the first IVF-ET baby in Japan. In 1986, he established Suzuki Memorial Hospital, which specializes in IVF-ET therapy. He served as the head of the hospital to disseminate IVFET techniques to medical institutions throughout Japan. He is an honorable member of many academic societies in Japan. Since 1987, he has been serving as the director of Suzuki Memorial Hospital and continues working on ART. 